\title{
Influence of Natural and Artificial Soil Conditioners on Water Holding Capacity and Hydraulic Conductivity of Sandy Soils
}

\author{
Faisal Zeineldin $^{1, *}$, Khalid Biro ${ }^{1}$, Abdulrahman O. Alghannam ${ }^{2}$ \\ ${ }^{1}$ Water Studies Centre, King Faisal University, Al-Hofuf, Al-Hassa 31982, Saudi Arabia. \\ ${ }^{2}$ Faculty of Agricultural Sciences and Food Science, Al-Hofuf, Al-Hassa 31982, Saudi Arabia.
}

\begin{abstract}
How to cite this paper: Faisal Zeineldin, Khalid Biro, Abdulrahman O. Alghannam. (2021) Influence of Natural and Artificial Soil Conditioners on Water Holding Capacity and Hydraulic Conductivity of Sandy Soils. International Journal of the Science of Food and Agriculture, 5(2), 219-227.
\end{abstract}

DOI: 10.26855/ijfsa.2021.06.003

Received: February 28, 2021

Accepted: March 26, 2021

Published: April 13, 2021

*Corresponding author: Faisal Zeineldin, Water Studies Centre, King Faisal University, Al-Hofuf, Al-Hassa 31982, Saudi Arabia.

Email: fzeineldin@kfu.edu.sa

\begin{abstract}
Hot climatic condition of arid and semi-arid regions trigger rates of high evaporative water demand on the cultivated areas. Also, domination of coarse textured soils has negative impact on water use efficiency and nutrient availability. Coarse textured soils, sandy or loamy sand soils, dictated most soils of the agricultural regions of Kingdom of Saudi Arabia (KSA). Therefore, there is a need for adoption of appropriate agricultural practices of water conservation. Hydraulic properties of the coarse textured soils enhance drainage of irrigation water and nutrient away below the root zone. The objective of the study was to investigate influence addition of super-absorbent polymer as an artificial conditioner, dry cattle manure, date palm biochar and clay soil as natural conditioners on hydraulic properties of sandy soils. Water holding capacity (WHC) of amended sandy soils by the conditioners were evaluated against varying low soil matric tensions $(-0.2,-0.4$, $-0.6,-0.8$ and -1 bars). Saturated hydraulic conductivity (Ks) of the amended sandy soils was assessed in laboratory with a digital pressure censored apparatus. The outcomes showed all conditioners except the polymer enhanced the retention ability of sandy soils and decreased the Ks. WHC of the amended sandy soils increased by $379 \%, 200 \%, 74 \%$ and $32 \%$, respectively, due to addition of $10 \%$ date palm biochar, $0.4 \%$ K-HCP polymer, $10 \%$ silt-clay-loam soil and $10 \%$ cattle manure. The Ks of sandy soil (control) decreased by $74 \%, 59 \%$ and $47 \%$, respectively, due to addition of date palm biochar, silt-clay-loam, and cattle manure, but to the K-HCP polymer increased by $31 \%$. Natural soil conditioners attested to be very effective in improving WHC and reducing Ks of sandy soils.
\end{abstract}

\section{Keywords}

Sandy Soils, Water Holding Capacity, Saturated Hydraulic Conductivity, Polymer, Dry Cattle Manure, Biochar, Clay Soil

\section{Introduction}

Sandy soils contained rocks (limestone, quartz and granite) and mineral particles. The geological origin, shape and size of the soil mineral components affect the hydro-physical properties of a soil such as water holding capacity and hydraulic conductivity $[1,2]$. Sandy soils have more than $50 \%$ sand content and cover $18 \%$ of the land surface of the Earth [3]. Coarse textured soils (Sand, sandy loam, loamy sand) dominated most cultivated areas of the Kingdom of Saudi Arabia (KSA). In the KSA, sandy soils comprised $70-90 \%$ sand, $0-30 \%$ silt, and $0-15 \%$ clay and characterized by low water holding capacity due to small specific surface of sand particles $[4,5]$. The higher silt percentage and clay sized particles in a soil, the higher its water holding capacity. Texture of sandy soils in the KSA varies from vary from 
fine to coarse sand with very low clay content (0-3\%), depending on soil particles distribution. Accordingly, WHC varies from high to low while the Ks from low to high. Saturated hydraulic conductivity (Ks) is an essential soil physical property that controls transmit of water within the locality of a root zone, and influences all soil-plant-water relations, and processes [6]. The Ks is associated with the soil texture and structure; therefore, is one of most important variable properties. Cultivated areas of Al-Ahsa oasis in eastern region of the Kingdom dominated mostly by sandy soils, which triggered in forming two vast evaporation lakes (Aleyoon and Alsfer lakes) from drainage of irrigation water. The existence of the lakes for decades reflects how significant continuous amount of agricultural drainage water kept flowing into the lakes. Low WHC and high Ks of the sandy soils at oasis are the main factors leading to excessive drainage of irrigation water below the root zone [7]. Water holding capacity of a soil is a limiting factor to soil water distribution and availability of nutrients to plants [8]. Sandy soils reach their saturation points in shorter time as compared to clay soils and any excess water after the saturation drainage below the vicinity of the root zone. Gravity and slope towards the Arabic gulf also facilitate the flowing of drainage water to the lakes. Nevertheless, the increase in the adoption of micro-irrigation and drip irrigation systems on the oasis, there is significant waste to the irrigation water carrying nutrients because of the inappropriate management of these modern irrigation systems.

Application of soil organic matters, i.e. farmyard manure (FM), earthworm manure (EM) and walnut sawdust (WS) increased available water holding capacity $(\mathrm{p}<0.01)$ of the sandy soils [9]. The amendment by $8 \%$ of the FM, EM, and WS decreased the Ks by 51\%, 39\% and 35\%, respectively. Manure addition to sandy soils designated by number of studies in improving soil water retention, soil water, and nutrient availability for plants [10,11, 12]. A study in Nebraska showed amendment of a fine sandy loam by cattle manure retained $18 \%$ more soil water at -0.33 bars and $20 \%$ more at -15 bars, along with $16 \%$ more plant available water [10]. Moreover, attraction of the sandy soil for water increased with the increase of the organic matter content.

Biochar is a carbon-rich natural soil conditioner produced from thermal decomposition of different organic material at temporaries less than $700{ }^{\circ} \mathrm{C}$ in the absence of the oxygen $[4,5,13]$. The biochar soil conditioner is well known for its positive potential impacts, which included carbon sequestration, improved crop yield and enhance water retention. Loamy sand's WHC increased by $233 \%$ and $133 \%$ when mixed by rate of $10 \%$ switchblade grass biochar and hemlock biochar respectively [14]. Water holding capacity of sandy loam soil (16\%), doubled when amended by $9 \%$ mass of woody biochar of yellow pine from pyrolysis at $400{ }^{\circ} \mathrm{C}$ [15]. Biochar amendment with an application rate of $20 \mathrm{t} \mathrm{ha}^{-1}$ without fertilization found to increase the bulk density by $12 \%$ and reduced the porosity by $12 \%$ [16].

Amending of sandy loam soils with inorganic amendments (nanoclay, vermiculite and zeolite) was shown as an effective practice in reducing leaching of $\mathrm{NH}_{4}-\mathrm{N}$ and improving $\mathrm{N}$ fertilizer efficiency [17]. Clay soil amendment with an optimum application rate of $24 \mathrm{Mg} /$ ha bentonite, had positive impacts on a soil WHC and crop growth [18]. The volumetric water content at $100 \mathrm{KPa}$ and micro aggregate $(0.25-2 \mathrm{~mm})$ of nanoclay treated-sandy soils were significantly $(\mathrm{P}>0.05)$ increased [19]. Addition of bentonite and nano bentonite to sandy soils resulted in increasing available water, WHC and availability of macronutrients [20]. Bentonite is natural soil amendment that can enhance soil water content, microbial activity and nutrient cycling [21].

Super-absorbent hydrogel polymers are highly cross-linked polyacrylamide polymers, made up of water-insoluble acrylamide and potassium acrylate, [-CH2-CH (COOK)-] $\mathrm{n}$. They used in agriculture to enhance the water-holding capacity of sandy soils. Leaching of polymer amended sandy soil with tab water caused decrease in the Ks but followed by steady increase, while leaching with distilled water caused decrease of the Ks [7]. Number of studies stated superabsorbent polymers are capable of improving the physic-chemical properties of sandy soils [22, 23, 24, 25]. Addition of superabsorbent polymer found to enhance absorbing and retaining abilities of sandy soils and to enable gradual releasing of soil water and nutrients for plants uptake. Adding 4 grams of two superabsorbent polymers (Super AB A200 and Herbosorb) to a kilogram of sandy soil increased soil available water by 350 and 320 respectively [26]. When highly crossed-linked polyacrylamide polymer (Stockosorb ${ }^{\circledR} \mathrm{K} 400$ ) added to a sandy soil at varying concentrations $(0.04 \%$, $0.08 \%, 0.12 \%, 0.20 \%$ and $0.4 \%$ weight by weight), the highest concentration $(0.4 \%)$ changed the WHC from typical sand soil to loamy or silty clay soil [13]. The objective of the study was to evaluate the influence of three natural conditioners, dry cattle manure, rich-clay soil, and biochar and an artificial conditioner, namely K-Highly Crossed-linked Polyacrylamide Polymer (K-HCP) polymer on water holding capacity and on the saturated hydraulic conductivity of sandy soils.

\section{Materials and Methods}

\subsection{Soil and Soil Conditioners}

At the Research and Training Station (RTS) of King Faisal University, dry cattle manure was collected from an animal farm, while sandy and clay soils were from fields. Then individually were air dried, grounded and sieved by $2 \mathrm{~mm}$ mesh screen. The biochar was made from khalas cultivar date palm leaves by a small-scale pyrolysis system. Then was crushed by hand and sieved to collect particles sized $<2 \mathrm{~mm}$, as recommended for agricultural application. Addition of 
$10 \%$ dry cattle manure, $10 \%$ silt-clay-loam soil, $0.4 \% \mathrm{~K}-\mathrm{HCPP}$, and their mixture weight by weight were used in the amendment of sandy soil (control) along with addition of $5 \%$ and $10 \%$ biochar of khalas date palm leaves.

\subsection{Polymer Pre-hydrated Hydrogel}

The K-HCP is superabsorbent hydro-gel polymer and it is an insoluble organic compound. Pre-hydrated hydrogel of the K-HCP polymer was prepared by mixing thoroughly 12.5 grams of the polymer dry powder (Stockosorb ${ }^{\circledR} 500$ micro) in one-liter of tab water $(1.3 \mathrm{dS} / \mathrm{m})$. The polymer powder to be left into the water for almost 30 minutes then was stirred several times until no more absorption or swelling. Retention and release abilities of the pre-hydrated hydrogel of the K-HCP polymer to water was examined against selected varying soil matric suctions $(-0.1,-0.3,-0.5,-0.7,-0.9,-1$, $-3,-5,-10$, and -15 bars), using pressure plate apparatus. In addition, the dehydration ability of the polymer was assessed under the sun heat for 30 days in summer and then the rehydration ability.

\subsection{Water Holding Capacity}

Water holding capacity at -0.33 bar and the wilting point at -15 bar and total available water (TAW) of the amended sandy soils were determined using a pressure plate apparatus. The formula of American Society for Testing and Materials (8) used to determine the WHC on mass basis, as written follows:

$$
\mathrm{WHC}=\frac{\text { mass }_{\text {wetsampl }} e^{- \text {mass drysmaple }}}{\text { mass drysample }} \times 100 \%
$$

In addition, soil moisture content of the sandy soil and the amended sandy soils were evaluated against a range of low soil matric suctions (-0.0, $-0.2,-0.4,-0.6,-0.8$, and -1 bars).

\subsection{Saturated Hydraulic Conductivity}

Impacts of the addition of soil conditioners on saturated hydraulic conductivity of sandy soils were measured using a Bench-Top Ks smart device as shown in Figure 1. The device connected to a computer with USB to determine measurement of soil sample Ks via an interactive program. The measurement of the device for Ks based on the principle of Darcy's law. Initially, soils were packed into the device's samplers (each a size of $250 \mathrm{~cm}^{3}$ ) by a process of maneuvering and tapping up to a specific density based on soil type. Since there were no volume change occurred upon saturation of sandy soil or silty clay loam soil, their density was set to be $1.56 \mathrm{~g} / \mathrm{cm}^{3}\left(390 \mathrm{~g} / 250 \mathrm{~cm}^{3}\right)$, typical to soil's density of the cultivated areas in the KSA. However, densities for sandy soil amended by the polymer, dry cattle manure and conditioners mixture (silty clay loam soil + K-HCP polymer and dry cattle manure) were set to be $1.27,1.33 \mathrm{and} 1.2 \mathrm{~g} / \mathrm{cm}^{3}$ respectively. This is because their volume change upon saturation. Initially all soil samples were saturated overnight from bottom to top with a tap water $(1.3 \mathrm{dS} / \mathrm{m})$.

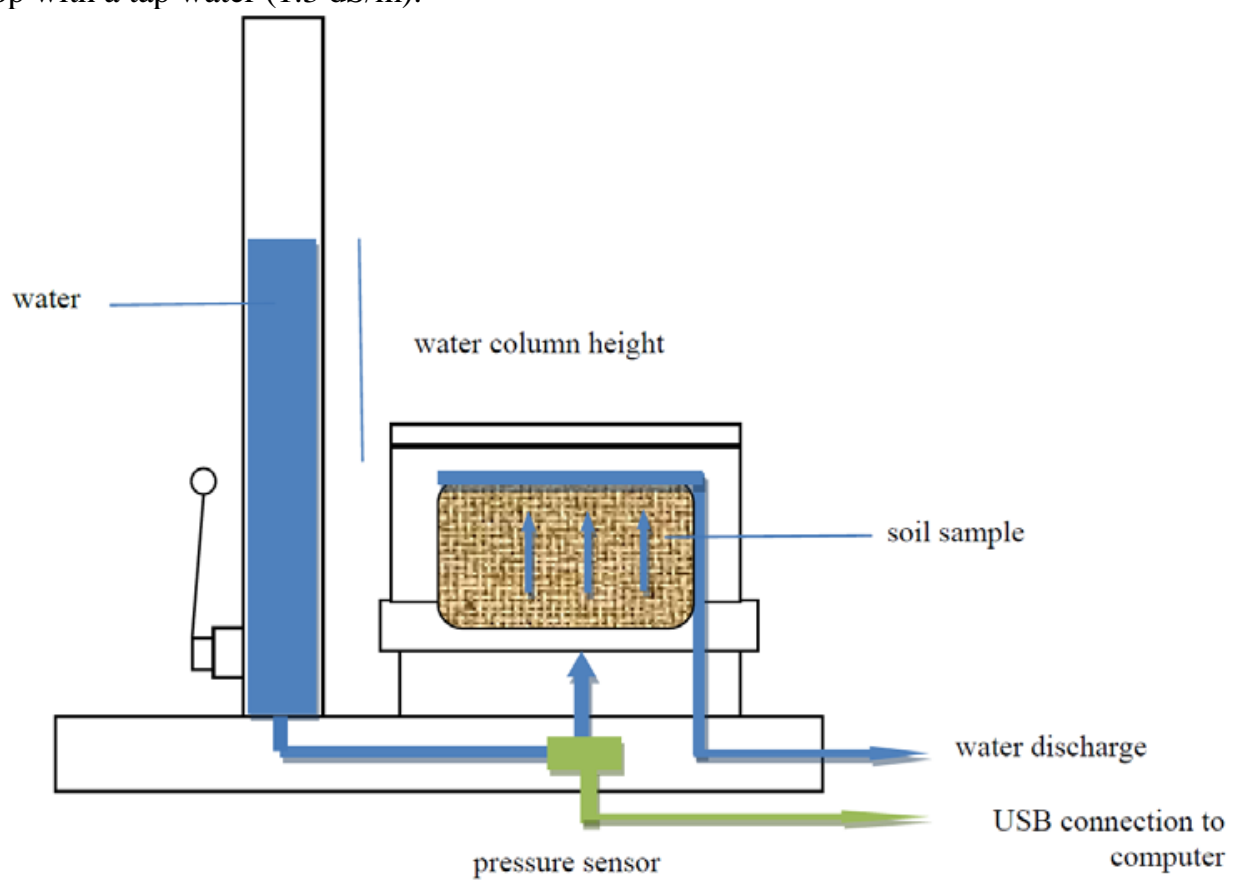

Figure 1. Bench-Top $K_{s}$ measuring device. 
Falling head option (water column), from $5 \mathrm{~cm}$ head, was chosen for to measure Ks of all amended soils and the control. The pressure sensor of the device is to detect the hydraulic gradient, the driving force for volumetric water flux density, Q, which passes through a soil sample column. The coefficient of the saturated hydraulic conductivity, Ks, as shown by equation 3, was derived from Darcy's relations of equation 2. Equation 3 is embedded into the interactive program in the computer to estimate the Ks of the soil sample, where the water flux density, Q, multiplied by the soil sample, $\mathrm{L}$, divided by soil sample area $\mathrm{A}$ and time $\mathrm{t}$, and hydraulic difference $\Delta \mathrm{H}$ along the flow direction.

$$
\begin{aligned}
& \mathrm{q}=\frac{\mathrm{Q}}{\mathrm{At}}=\mathrm{K}_{\mathrm{s}} \frac{\Delta \mathrm{H}}{\mathrm{L}} \\
& \mathrm{K}_{\mathrm{s}}=\frac{\mathrm{QL}}{\mathrm{At} \Delta \mathrm{H}}
\end{aligned}
$$

where

$$
\begin{aligned}
& \frac{\mathrm{Q}}{\mathrm{At}}=\text { water flux density } \\
& \frac{\Delta \mathrm{H}}{\mathrm{L}}=\text { hydraulic gradient }
\end{aligned}
$$

\section{Results and Discussion}

\subsection{Soils Texture Evaluation}

Based on the mechanical analyses of soils and USDA classification, the sandy soil (control) was classified as medium sand soil (52.03\%), as shown by particles distribution in Table 1 . There were no significant difference between the percent of coarse (18.7\%) and the fine sand (21.2\%), while the total percent of silt and clay separate was less than one. The clay soil, which was used as a natural conditioner, was texturally classified as silt clay loam soil (49.2\% silt, 37.3\% clay, $13.5 \%$ sand).

Table 1. Sandy soil particles distribution

\begin{tabular}{cccc}
\hline Soil Separate & Diameter ranger (millimeters) & Sandy soil particles percent distribution & Cumulative percent \\
\hline Gravel & 2.0 and larger & 0.00 & 0.00 \\
Very Coarse Sand & $2.0-1.0$ & 1.25 & 1.25 \\
Coarse Sand & $1.0-0.5$ & 18.66 & 19.91 \\
Medium Sand & $0.5-0.25$ & 52.03 & 71.94 \\
Fine Sand & $0.25-0.1$ & 21.21 & 93.15 \\
Very Fine sand & $0.1-0.05$ & 6.10 & 99.25 \\
Fines (silt + clay) & $<0.05$ & 0.75 & 100 \\
\hline
\end{tabular}

\subsection{Polymer Properties Assessment}

The assessment outcomes revealed the retention ability of the K-HCP polymer decreased with increase of the soil matric suction, as presented in Table 2, and vice versa for the release ability of the polymer. The hydration of the polymer showed it is capable of absorbing about $80 \%$ of its dry weight and releasing up to about $83 \%$ of the absorbed water at wilting point as shown in Table 2. The average electrical conductivity $\left(E C_{w}\right)$ of the released water during a range of soil matric suction (-0.1 to -15 bars) was $4.1 \mathrm{dS} / \mathrm{cm}$, which can be diluted when is mixed with sandy soil. The retention ability of the K-HCP polymer at field capacity ( $\mathrm{FC}=-0.33$ bars) and wilting point (WP $=15$ bars), the K-HCPP were $62.6 \%$ and $17.1 \%$ respectively. This indicated the polymer has the potential to enhance conservation of irrigation water within vicinity of the root zone and decrease drainage of water. Therefore, the K-HCP polymer has a high total available water (TAW= FC-WP), about $45.5 \%$, nine folds of the TAW of the sandy soil.

The maximum dehydration ability of the K-HCP pre-hydrated hydrogel polymer when subjected to sun heat of summer days $\left(45-48^{\circ} \mathrm{C}\right)$ was about $90 \%$ of its weight. However, its rehydration ability observed to be much slower and less than the initial hydration, approximately saturation up about $60 \%$ as shown Figure 2. 
Table 2. Retention and release abilities of K-HCP polymer

\begin{tabular}{|c|c|c|c|}
\hline Soil matric Suction & Released Water & Retained Water & $\mathrm{EC}_{\mathrm{w}}$ of released water \\
\hline bars & $\%$ & $\%$ & $\mathrm{dS} / \mathrm{cm}$ \\
\hline-0.1 & 28.4 & 71.6 & 4.2 \\
\hline-0.3 & 37.4 & 62.6 & 4.1 \\
\hline-0.5 & 46.0 & 54.0 & 4.3 \\
\hline-0.7 & 51.0 & 49.0 & 4.2 \\
\hline-0.9 & 52.2 & 47.8 & 3.8 \\
\hline-1 & 55.4 & 44.6 & 3.7 \\
\hline-3 & 68.4 & 31.6 & 4.9 \\
\hline-5 & 71.0 & 29.0 & 3.7 \\
\hline-10 & 76.1 & 23.9 & 3.2 \\
\hline-15 & 82.9 & 17.1 & 4.4 \\
\hline
\end{tabular}

Figure 2. Dehydration and rehydration of the K-HCP polymer pre-Hydrated hydrogel.

\subsection{Effects on WHC}

The influence of the addition of the K-HCP polymer and the soil natural conditioners on WHC of sandy soils are presented by Figure 3. In this study, low soil matric suctions (-0.1, $-0.2,-0.3,-0.4,-0.5,-0.6,-0.7,-0.8,-0.9$ and -1 bars) were assessed because most of the readily available water for plant uptake is between 0.0 to-1.0 bars, and it is important for irrigation scheduling. The results revealed the WHC of the amended sandy soils increased by $379 \%, 200 \%, 74 \%$ and $32 \%$ due to addition of $10 \%$ date palm biochar, $0.4 \%$ K-HCP polymer, $10 \%$ silt-clay-loam soil, and $10 \%$ cattle manure, respectively. Addition of the soil conditiners mixture, enhanced the WHC of sandy soil about $20 \%$ more than the effect of K-HCP-Polymer addition, as shown in Table 3.

The outcomes indicated the K-HCP-Polymer has potential to increase WHC of sandy soil by 2 to 3 folds, while the natural conditioners (silt-clay-loam soil and the manure) by $1 / 2$ to 1 folds. Below 0.4 bar suction, the effect of conditioners mixture addition (polymer + silt-clay-loam soil+ dry-cattle-manure) on WHC of sandy soil, as shown in Figure 3, was more profound than the effect of the K-HCP polymer.

Table 3. Impact of soil conditioners addition on water holding capacity of sandy soils

\begin{tabular}{cccc}
\hline $\begin{array}{c}\text { Amended sandy soils (Sandy soil + soil condition- } \\
\text { er) }\end{array}$ & WHC mass-basis $\left(\mathrm{w}_{\mathrm{H} 2 \mathrm{O}} / \mathrm{w}_{\mathrm{dry}}{ }^{*} 100\right)$ & STDEV & WHC percent change \\
\hline Sand (control) & 6.82 & \pm 0.54 & 0 \\
Sand + 0.4\% K-HCP-Polymer & 20.6 & \pm 2.96 & +200.1 \\
Sand + 10\% cattle-manure & 8.98 & \pm 0.65 & +31.6 \\
Sand + 10\% silt-clay loam soil & 11.86 & \pm 1.2 & +73.9 \\
Sand + 0.4 K-HCP-Polymer + 10\% cattle-manure + & 21.8 & \pm 4.42 & +219.5 \\
10\% silt-clay loam soil & 32.7 & \pm 2.1 & +379 \\
Sand + 10\% biochar & 14.6 & 1.9 & +114.1 \\
Sand +5\% biochar & & \\
\hline
\end{tabular}




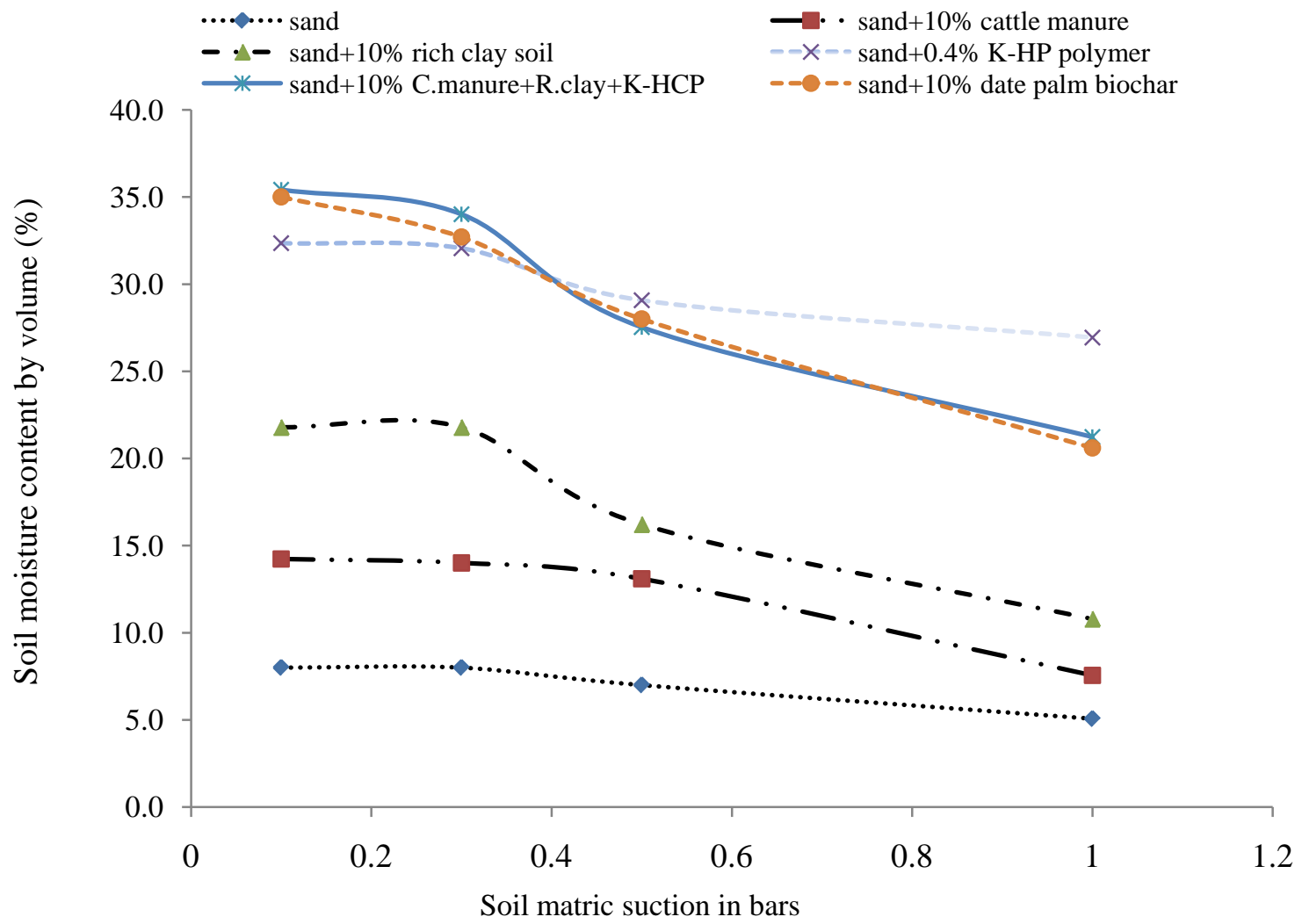

Figure 3. Water holding capacity of amended sandy soils.

\subsection{Effects on $K_{s}$}

Impacts of the addition of the hydrogel K-HCP polymer and the soil natural conditioners on saturated hydraulic conductivity of sandy soils were revealed in Table 4 . Addition of $0.4 \% \mathrm{~K}-\mathrm{HCP}$ polymer increased the Ks of sandy soil in range of $27-36 \%$, with average of $30.5 \%$ increase. Addition of $10 \%$ date palm biochar, $10 \%$ rich clay soil (silt clay loam), and $10 \%$ cattle manure on mass basis, reduced the Ks of the sandy soil by $74 \%, 59 \%, 47 \%$ respectively. Although the addition of the mixture of $0.4 \% \mathrm{~K}-\mathrm{HCP}$ polymer, $10 \%$ cattle-manure and $10 \%$ silt-clay loam, enhanced the WHC of the sandy soil, but in the same time increased the Ks by $26 \%$, as shown in Table 4 . However, a very positive impact observed due to the addition of the mixture on an square meter of agrass as shown by Figure 4 . The growth and color of grass in treated area was much better growth and greenish as compared to the rest of field. This mixture could be useful to save irrigation water and as good source of organic nutrient fertilizers due to decompose of the cattle manure.

Table 4. Percent change of saturated hydraulic conductivity $\left(K_{s}\right)$

\begin{tabular}{cccc}
\hline Soil + soil conditioner & Ks average $\mu \mathrm{m} / \mathrm{s}$ & STDEV & Impact on $\mathrm{K}_{\mathrm{s}}$ as percent change \\
\hline Sand (control) & 98.1 & \pm 6.7 & 0 \\
Sand + 0.4\% K-HCP-Polymer & 128 & \pm 4.3 & +30.5 \\
Sand + 10\% cattle-manure & 52.4 & 3 & -46.6 \\
Sand + 10\% silt-clay loam soil & 40.7 & \pm 2.1 & -58.5 \\
Sand + 0.4\% K-HCP-Polymer + 10\% cattle-manure + 10\% & 123.5 & \pm 9.8 & +25.9 \\
silt-clay loam soil & 25.6 & \pm 10.1 & -73.9 \\
Sand +10\% biochar & 57.8 & \pm 4 & -41.08 \\
Sand +5\% biochar & & &
\end{tabular}



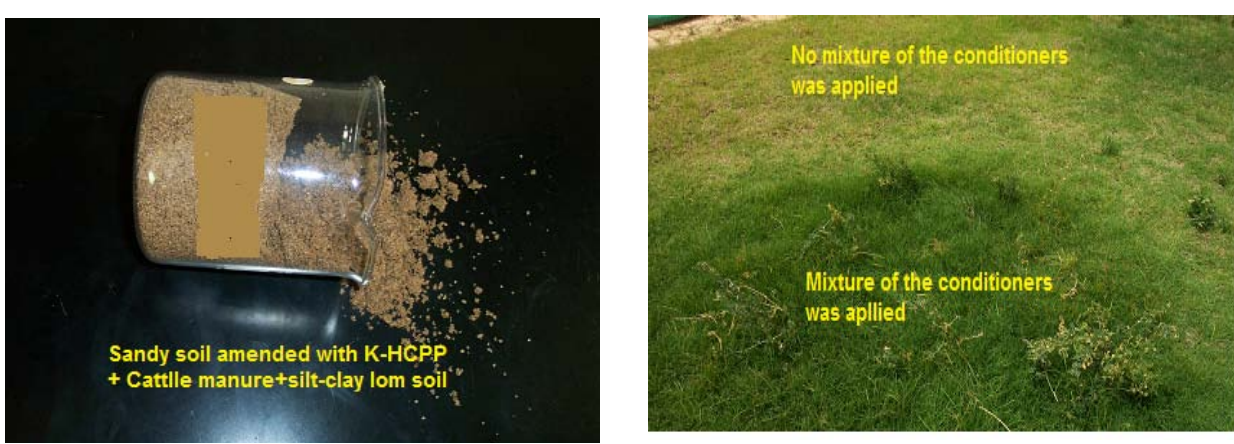

Figure 4. Impact of soil conditioners mixture (0.4\% HCPP, $10 \%$ cattle manure and $10 \%$ silty clay loam soil) on grasses grown on sandy soil.

\subsection{Date Palm Biochar Impacts}

Although impacts of the addition of $10 \%$ date palm biochar on the WHC and Ks of sandy soils were interesting and promising, but the $\mathrm{EC}_{\mathrm{e}}$ and $\mathrm{pH}$ of soil water extract of amended sandy soil were relatively high, i.e., $14 \mathrm{mS} / \mathrm{cm}$ and 9.9 respectively. The soil water extract obtained using standard saturation paste method for obtaining soil water extract. The ideal soil water condition for growing crops that $\mathrm{EC}_{\mathrm{e}}$ of the soil water extract should not exceed $4 \mathrm{dS} / \mathrm{cm}$ and $\mathrm{pH}$ should be about 7 . Accordingly, low rates of mixing of date palm biochar, $5 \%$ and $2 \%$, with sandy soils were investigated. The results as shown in Figure 5, the Ks of the amended sandy soil decreased with decreasing the added amount of the biochar. However, regarding the soil water extract, the $\mathrm{EC}_{\mathrm{e}}$ deceased by $50 \%$ when the rate of mixing decreased by $50 \%$, but on the other hand still the $\mathrm{pH}$ was high, above eight. The date palm biochar found to have the highest potential in improving hydraulic properties of sandy soil; therefore, saving irrigation water and reducing deep percolation water losses.

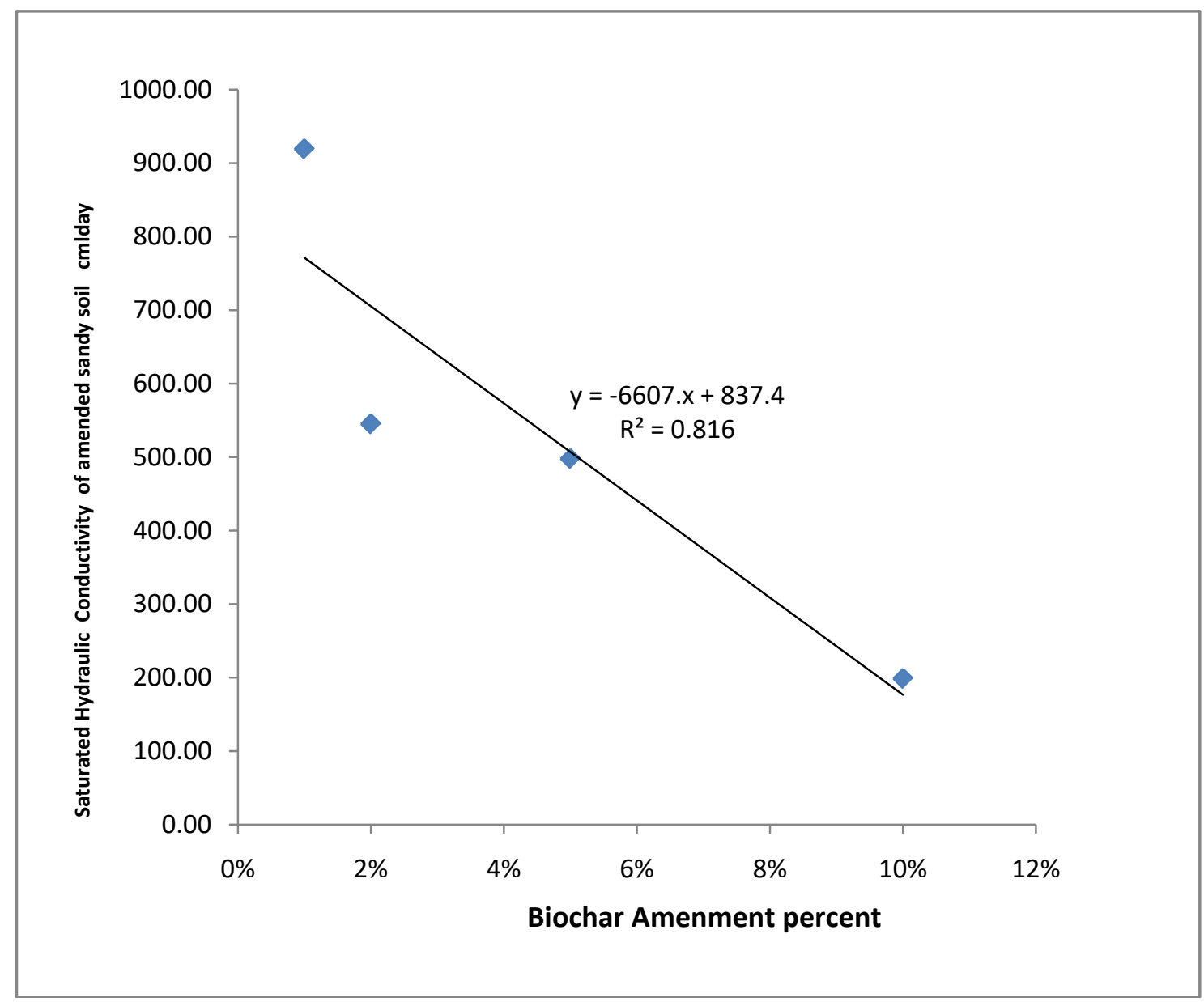

Figure 5. Saturated hydraulic conductivity as affected by the biochar amendment. 


\section{Conclusions}

All of the natural soil conditioners (date palm biochar, silt-clay-loam soil and cattle manure) and the artificial soil conditioner (K-HCP polymer) improved water holding capacity of sandy soils. That is irrespective totheir varying impacts from postive to negative on saturated hydraulic conductivity. The date palm biochar found to have the highest potential, as compared to other soil conditioners, in enhancing water holding capacity and minimizing deep percolation of sandy soil in the Kingdom of Saudi Arabia. Although there are some concerns regarding the high values of the $\mathrm{EC}_{\mathrm{e}}$ and $\mathrm{pH}$ of soil water extract sandy soil amended by the date palm biochar, but further investigation under way were to tackle the problem.

Despite, the artificial soil conditioner, K-HCP polymer, had the highest positive impact in improving water holding capacity of sandy soil, but at the same time had highest negative impact in increasing saturated hydraulic conductivity of amended sandy soil. Swelling of the K-HCP polymer increased the soil bulk density and inturn increased the soil porosity.

\section{Acknowledgements}

This paper supported by the facilities, laboratory and advanced equipment of Water Studies Center, King Faisal University; help of graduate students of food and agricultural sciences; self-Funded Research.

\section{References}

[1] Brouwer, J. and Anderson, H. (2000). Water holding capacity of ironstone gravel in a typic plinthoxeralf in southeast Australia. Soil Science Society of America Journal, 64: 1603-1608.

[2] Hillel, D. (2003). Introduction to Environmental Soil Physics. Elsevier. Amsterdam.

[3] USDA. (2010). Keys to Soil Taxonomy. Soil Survey Staff, Washington.

[4] Lehmann, J. and Joseph, S. (2009). Biochar for environmental management: Science and Technology. London, GB: Earthscan.

[5] Potter, S. R., Andrews, S., Atwood, J. D., Kellogg, R. L., Lemunyon, J., Norfleet, L., and Oman, D. (2006). Model Simulation of Soil Loss, Nutrient Loss, and Change in Soil Organic Carbon Associated with Crop Production. U.S. Department of Agriculture, Natural Resources Conservation Service, Conservation Effects Assessment Project Report.

[6] Gamie, R., De Smedt, F. (2018). Experimental and statistical study of saturated hydraulic conductivity and relations with other soil properties of a desert soil. European Journal of Soil Science, 69: 256-264.

[7] Bhardway, A. K., Shainberg, I., Goldstein, D., Warrington, D. N., and Levy, G. J. (2007). Water Retention and Hydraulic Conductivity of Cross-linked Polyacrylamides in Sandy Soils. Soil Science Society of American Journal, 71, 2; Proquest, p. 406.

[8] Maraseni, T. N. (2010). Maximizing the benefits. International Journal of Environmental Studies, 67, 319-327.

[9] Demir, Y. and Dogan, D. A. (2019). The effect of organic matter applications on the saturated hydraulic conductivity and available water-holding capacity of sandy soils. Applied Ecology and Environmental Research, 17(2): 3137-3146. DOI: http://dx.doi.org/10.15666/aeer/1702_31373146.

[10] Humberto, B., Gary, W. H., and Rex, A. N. (2015). Cattle manure application reduces compatibility and increases water retention. Soil Sci. Soc. Am. J., 79: 212-223.

[11] Walia, M. K., Walia, S. S., and Dhaliwal, S. S. (2010). Long-term effect of integrated nutrient management of properties of Typic Ustochrept after 23 cycles of an irrigated rice (Oryza sativa L.)-wheat (Triticum aestivum L.) system. J. Sustain. Agric., 34: 724-743. doi:10.1080/10440046.2010.507519.

[12] Zhang, S., Yang, X., Wiss, M., Grip, H., and Lovdahl, L. (2006). Changes in physical properties of a loess soil in China following two long-term fertilization regimes. Geoderma, 136: 579-587. doi:10.1016/j.geoderma.2006.04.015.

[13] Huttermann, A., Zommorodi, M., and Reise, K. (1999). Addition of hydrogels to soil for prolonging the survival of Pinus halepensis seedlings subjected to drought. Soil and Tillage Research. Volume 50, Issues 3-4. Pp. 295-304.

[14] Yu, O. Y., Harper, H., Hoepfl, M., and Domemuth, D. (2017). Characterization of Boichar and its Effects on Water Holding Capacity of Loamy Sand Soil: Comparison of Hemlock Biochar and Switchblade Grass Biochar Characteristics. Environmental Progress and Sustainable Energy, Vol. 36, No. 5, pp. 1474-1479.

[15] Yu, O. Y., Brian, R., and Sam, S. (2013). Impact of biochar on water holding capacity of loamy sand soil. International Journal of Energy and Environmental Engineering. http://www.jounal.ijeee.com/content/4/1/44.

[16] Toková, L., Dušan, I., Ján, H., and Elena, A. (2020). Effect of Biochar Application and Re-Application on Soil Bulk Density, Porosity, Saturated Hydraulic Conductivity, Water Content and Soil Water Availability in a Silty Loam Haplic Luvisol. Agronomy, 10, 1005. Doi: 10.3390/agronomy10071005.

[17] Mazloomi F. and Jalali, M. J. (2019). Effects of vermiculite, nanoclay and zeolite on ammonium transport through saturated sandy loam soil: Column experiments and modeling approaches. Catena, 176: 170-180. https://doi.org/10.1016/j.catena.2019.01.014.

[18] Mi, J., Edward, G. G., Shengtao, X., Neil, B. M., Bin, M., and Jinghui, L. (2020). Effect of bentonite as a soil amendment on field water-holding capacity, and millet photosynthesis and grain quality. Scientific Reports, 10: 18282. 
https://doi.org/10.1038/s41598-020-75350-9. Nature research.

[19] Padidar, M., Ahmad, J., Kamran, A., Majid, A., Payam, N., Naser, H, and Jaber, F. (2016). The impacts of nanoclay on sandy soil stability and atmospheric dust control. Agriculture Conspectus Scientificus. Vol. 81, No. 4 (pp. 193-196).

[20] El-Nagar, D. A., Dalal, H. S. (2021). Synthesis and characterization of nano bentonite and its effect on some properties of sandy soils. Soil \&Tillage Research, 208: 104872. https://doi.org/10.1016/j.still.2020.104872.

[21] Mi, J., Gregorich, E. D., Xu, S., McLaughlin, N. B., Ma, B., and Liu, J. (2021). Changes in soil biochemical properties following application of bentonite as a soil amendment. European Journal of Soil Biology, $102: 103251$. https://doi.org/10.1016/j.ejsobi.2020.103251.

[22] Abd El-Rehim, H. A., El-Sayed, A., Hegazy, A., and Abd El-Mohdy, H. L. (2004). Radiation Synthesis of Hydrogels to Enhance Sandy, Soils Water Retention and Increase Plant Performance. Journal of Applied Polymer Science, 2004, Volume 93, Issue 3.

[23] Abd El-Rehim, H. A., El-Sayed, A. Hegazy A., Abd El-Mohdy, H. L. (2006). Effect of various Environmental conditions on the Swelling property of PAAm/PAAcK superabsorbent hydrogel prepared by ionizing radiation. Journal of applied Polymer science, Volume 101, Issue 6.

[24] Silberbush, M., Adar, E., and Malach, Y. De. (1993). Use of an hydrophilic polymer to improve water storage and availability to crops grown in sand dunes II. Cabbage irrigated by sprinkling with different salinities. Agricultural Water Management. Vol. 23, Issue 4. Pp. 315-327.

[25] Sivapalan, S. (2001). Effect of polymer on soil water holding capacity and plant water use efficiency. Proceedings of the 10th Australian Agronomy Conference, Australian Society of Agronomy.

[26] Heyder, A. K., Narges, Z. (2013). The Effect of Superabsorbent Polymers on the Water Holding Capacity and Water Potential of Karkhe Noor Sandy Soils. International Journal of Scientific Research in Knowledge (IJSRK), 1(9), pp. 317-324. 